\title{
Application Research on the Effectiveness Value of Cooperation and Diversification of Basketball Teaching Methods in Colleges
}

\author{
Chuan-hua Shi, Gui-qi Yang \\ Nantong Institute of Technology \\ Nantong Jiangsu 226602 China
}

\begin{abstract}
In order to improve the effect of basketball learning, the state pays more attention to college sports, and the diversified basketball reform is also constantly pushing forward. The application of diversified teaching methods in college basketball teaching, combined with self-efficacy value theory, aims to improve the effect of basketball teaching through students' experience of success, the guidance of students' reasonable attribution, and cultivation of students' self-confidence in learning. Firstly, this work analyzed the significance of diversified teaching mode to college sports basketball teaching, and then, discussed the application of diversified teaching mode in college sports basketball teaching, aiming at improving the quality of college sports basketball teaching and improving the physical quality of college students, finally, put forward to improve the effect of basketball learning by enhancing the effectiveness value of basketball learning.
\end{abstract}

Keywords_Diversified Teaching Mode; Basketball Teaching; Effectiveness Value

\section{INTRODUCTION}

Basketball is a popular ball game all over the world. Because of its openness, it has been recognized and welcomed by people, and it has become a sport with rich social culture and strong penetration. The deepening reform of colleges and universities urges colleges and universities to pay more attention to the cultivation of high-quality talents, which requires the combination of teaching content and structure[1]. Harmonious teaching atmosphere adhering to the educational principle of keeping pace with the times, practicing modern educational theory, which realizing the combination of theory and practice, cultivating students' enthusiasm for basketball participation, and gradually cultivating students' awareness of lifelong sports. As a very popular sport, basketball has been welcomed by students, but in basketball teaching. In the process of learning, the teacher trains basketball skills, but neglects the cultivation of students' physical adaptability and flexibility, pays attention to the promotion of basketball, realizes the effective integration of multiple disciplines, develops diversified teaching mode, adheres to the teaching principles of keeping pace with the times and upholds modernization[2]. Educational theory trains high-quality talents in line with the needs of social development.

In the traditional physical education teaching process, the university physical education teachers usually demonstrate the basic basketball skills to all the students at the beginning of the physical education class, and then let the university students spend the rest of the time practicing the basic basketball skills demonstrated by the university physical education teachers[3]. College students have gradually lost interest in basketball teaching. The diversified basketball teaching mode is a modern scientific and effective teaching concept for college students, which can arouse their enthusiasm in class. Moreover, diversified basketball teaching mode can make college PE teachers flexibly change their teaching methods according to their teaching contents. The teaching methods of diversified teaching mode in college basketball teaching mainly include the discovery learning method, cooperative learning method, mastery learning method, procedure learning method and micro-learning method[4].

Diversified teaching mode plays a very important role in the teaching process. It not only promotes students' personality development but also has a very important influence on students' physical and mental development[5]. Diversified teaching mode, with the characteristics of subjective initiative and flexibility, plays a vital role in college sports basketball teaching. This paper expounds on the significance of diversified teaching mode in college sports basketball teaching, and discusses the application of diversified teaching mode in college sports basketball teaching, aiming at improving the quality of college sports basketball teaching and improving the physical quality of college students. To improve the effect of basketball learning by enhancing the effectiveness value of basketball learning.

\section{The SignificAnce OF Diversified TeACHING Mode IN COLLEgE BASKETBALl TEACHING}

College basketball teaching has a history of more than sixty years. Whether it is basketball teaching materials, facilities, teaching methods, etc., are constantly innovating, but there are still many shortcomings, which directly affect the actual teaching effect. Diversified teaching methods can effectively remedy existing problems in traditional teaching. To improve the efficiency of basketball teaching in colleges and universities. According to the current situation of relatively inadequate teaching resources, great differences in students' technical basis and less class hours in basketball general course teaching in physical education colleges and departments, combined with the research results of modern learning theory, and making full use of the network teaching resources vigorously developed by colleges and universities, the 
diversified combination teaching is applied to the body[6]. The implementation procedure of basketball teaching in the

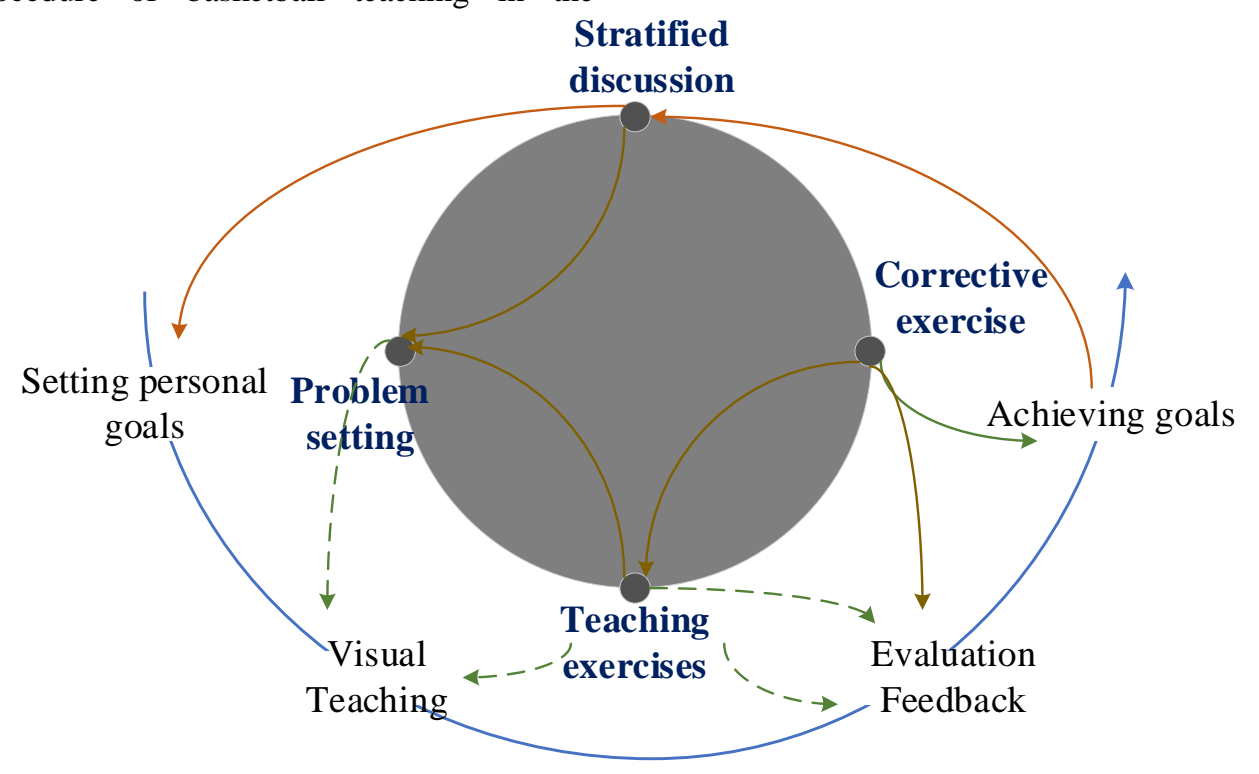

Fig.1. The program map for the implementation of diversified combination teaching

\section{METHODS AND RESUlTS}

\section{A. Experimental methods}

In the basketball course teaching, the method of improving students' self-efficacy is compared with traditional teaching. Through the analysis of the experimental results, the influence of the cultivation of self-efficacy on the basketball learning effect of college students is verified.

Taking two classes as the research object, one of the classes is an experimental class, and the students' self-efficacy is achieved through success or failure experience, alternative department of education is shown in Fig. 1.

\begin{tabular}{|c|c|c|c|c|}
\hline Effectiveness value factor & Experimental group & Control group & $\mathrm{T}$ & $\mathrm{P}$ \\
\hline Success or failure experience & $19.45 \pm 2.36$ & $19.52 \pm 2.12$ & 0.17 & $>0.05$ \\
\hline Alternative experience & $20.78 \pm 2.43$ & $20.37 \pm 3.20$ & 0.36 & $>0.05$ \\
\hline Speech and social persuasion & $16.49 \pm 2.71$ & $16.90 \pm 2.14$ & 0.55 & $>0.05$ \\
\hline Physiological and emotional states & $14.86 \pm 1.84$ & $14.59 \pm 2.81$ & 0.33 & $>0.05$ \\
\hline Total score & $70.49 \pm 5.71$ & $71.51 \pm 4.75$ & 0.35 & $>0.05$ \\
\hline
\end{tabular}

From Table I, it can be seen before the experiment, there was no significant difference in the total score of self-efficacy and various factors between the experimental class and the control class after T-test. Therefore, it can be considered that the subjects come from the same population. This experiment is a homogeneous comparison, which ensures that the experiment has high internal validity. experience, verbal and social persuasion, and effective methods of cultivating the effectiveness value of physical and emotional state in the basketball teaching process[7]. The sense is cultivated; the other class is used as a control class in the form of traditional basketball technique teaching. After the experiment, the sports performance value of the two classes and the mastery of basketball skills were tested, compared and analyzed to distinguish the differences between the two classes. To determine the impact of the cultivation of learning self-efficacy on the learning outcomes of college students' basketball[8].

TABLE II. T-TEST OF EFFECTIVENESS VALUE FACTORS AND TOTAL SCORES OF TWO GROUPS OF STUDENTS AFTER THE EXPERIMENT

\begin{tabular}{|c|c|c|c|c|}
\hline Effectiveness value factor & Experimental group & Control group & $\mathrm{T}$ & $\mathrm{P}$ \\
\hline Success or failure experience & $22.05 \pm 2.80$ & $20.52 \pm 2.43$ & 3.18 & $<0.01$ \\
\hline Alternative experience & $20.23 \pm 2.17$ & $20.35 \pm 3.20$ & 2.38 & $<0.01$ \\
\hline Speech and social persuasion & $18.58 \pm 2.48$ & $17.59 \pm 2.75$ & 2.54 & $<0.05$ \\
\hline Physiological and emotional states & $16.04 \pm 2.71$ & $14.82 \pm 1.89$ & 0.33 & $<0.05$ \\
\hline Total score & $78.90 \pm 5.53$ & $73.20 \pm 5.95$ & 3.38 & $<0.01$ \\
\hline
\end{tabular}


It can be seen from Table II that there are significant differences between the various factors and the overall level of physical self-efficacy of the experimental and control students. It can be explained that the intervention methods and means in the classroom to improve the self-efficacy factors can effectively cultivate and improve the college students' self-efficacy. The T-test $(\mathrm{M}+\mathrm{SD})$ of the total score of self-efficacy of the students in the control and experimental classes before and after the experiment is shown in Table III.

TABLE III. T-TEST OF TOTAL SCORES OF EFFICACY VALUES BETWEEN THE TWO GROUPS BEFORE AND AFTER THE EXPERIMENT

\begin{tabular}{|c|c|c|c|c|}
\hline Group & After the experiment & After the experiment & $\mathrm{T}$ & $\mathrm{P}$ \\
\hline Experimental group & $70.49 \pm 5.71$ & $78.90 \pm 5.53$ & 5.03 & $<0.01$ \\
\hline Control group & $71.51 \pm 4.75$ & $73.20 \pm 5.95$ & 1.79 & $>0.05$ \\
\hline
\end{tabular}

Table IV shows that the self-efficacy of female college students in the experimental class and the control class has been enhanced before and after the experiment. Only the self-efficacy of female college students in the experimental class has a significant difference before and after the experiment. In the teaching of an experimental class, teachers adopt four different intervention methods. They set up corresponding situations and targeted methods and means to teach according to the means. The students in the control class adopt the teaching methods often used in basketball teaching, without additional factors. The results are different, which can be analyzed as the result of teaching intervention methods. It shows that the teaching method designed according to the self-efficacy theory is effective and can greatly improve the self-efficacy of female college students. The traditional basketball teaching method has little effect on the improvement of female college students' self-efficacy, but it also improves to a certain extent. In order to shape a comprehensive person, the reform of physical education teaching should continue to deepen to serve the development of students.

TABLE IV. COMPARISON OF BASKETBALL TECHNICAL ACHIEVEMENTS BETWEEN THE EXPERIMENTAL GROUP AND THE CONTROL GROUP

\begin{tabular}{cccc}
\hline Project & Experimental group & Control group & P \\
\hline $4 * 28 m$ Inter-march Shooting/s & $49.23 \pm 6.96$ & $60.80 \pm 12.07$ & 0.07 \\
Shooting in 30 seconds & $7.46 \pm 1.75$ & $5.96 \pm 1.77$ & 0.02 \\
$4 * 15 m$ turn-back & $17.2 \pm 0.52$ & $18.80 \pm 0.62$ & 0.01 \\
\hline
\end{tabular}

After the experiment, three test tests on basic techniques were performed on the experimental group and the control group. The first two are the technical indicators of basketball learning, and the latter is the important physical fitness index of basketball learning. Through analysis, the experimental class has exceeded the control class in the scores of the three items, and the difference between the two is significant, and the T test, $\mathrm{P}<0.05$, so it can be seen that in the teaching, while learning to improve self-efficacy, the various techniques of basketball have also been greatly improved, mainly because the students' self-confidence has been strengthened and learned the correct return. Because I understand that I can't learn basketball well, it's not because I have the poor ability, but I am afraid of being tired and tired, and I don't take it seriously. Through a series of self-efficacy training, female college students found interest and confidence in this project. Let the students understand the sport in-depth, so it is precisely because of the improvement of self-efficacy that the students' enthusiasm and initiative to learn, the results of basketball learning naturally improve. Therefore, it can be judged that paying attention to the cultivation of students' self-efficacy in the technical teaching of basketball class is conducive to improving the performance of students' technical learning and has a good influence on teaching.

\section{CONCLUSION}

In a word, the continuous deepening of China's quality education reform has promoted continuous self-innovation in various basic education and higher education. As an important force in the cultivation of talents in China, college sports basketball teaching should adopt a diversified teaching mode to carry out special teaching and train more high-quality professionals for the development of our society. The diversified teaching method embodies the modern teaching principle of teacher-led and student-centered. The subjective status of students has been greatly respected in diversified teaching methods. Diversified teaching methods focus on the balanced and healthy development of knowledge, skills, methods and processes, emotional attitudes and values, and it promotes the development of students' personality, physical and mental health and the development of active learning concepts. Kinds of modern teaching methods can significantly improve the overall quality of college students and the effectiveness of basketball teaching.

\section{REFERENCES}

[1] Wan M W M, Wasiuzzaman S, Salleh N M Z N. Board and Audit Committee Effectiveness, Ethnic Diversification and Earnings Management: a Study of the Malaysian Manufacturing Sector[J]. Corporate Governance International Journal of Business in Society, 2016, 16(4).

[2] Gülşen E, Olivetti E, Freire F, et al. Impact of Feedstock Diversification on the Cost-Effectiveness of Biodiesel[J]. Applied Energy, 2014, 126(C):281-296.

[3] Vaquera A, J.V. García-Tormo, Ruano M A G, et al. An Exploration of Ball Screen Effectiveness on Elite Basketball Teams[J]. International Journal of Performance Analysis in Sport, 2017, 16(2): 475-485.

[4] Karol G, Bogusław S, Anna K. Impact of Regulation Change on Half-Court Offence in the Polish Basketball League[J]. Polish Journal of Sport \& Tourism, 2016, 23(2):70-75.

[5] Conte D, Favero $\mathrm{T}$ G, Niederhausen $\mathrm{M}$, et al. Determinants of the Effectiveness of Fast Break Actions in Elite and Sub-Elite Italian Men's Basketball Games[J]. Biology of Sport, 2017, 34(2): 177-183.

[6] Harvey, Stephen Smith, Megan L. Song Y, Robertson, David Brown, Renee Smith, Lindsey R. Gender and School-Level Differences in Students' Moderate and Vigorous Physical Activity Levels When Taught Basketball through the Tactical Games Model[J]. Journal of Teaching in Physical Education, 2016, 35(4): 349-357. 
[7] Marmarinos C, Apostolidis N, Kostopoulos N, et al. Efficacy of the "pick and roll" Offense in Top Level European Basketball Teams[J]. Journal of Human Kinetics, 2016, 51(1): 121-129.

[8] Feng S, Sheng S. Construction of Multifunctional Video Conversion-based Multimedia Teaching System for College Basketball[J]. International Journal of Emerging Technologies in Learning, 2018, 13(06): 176.

[9] Huang C, Zhang Y, Zhu C, et al. Chinese Sports Basketball Teaching Tactics Training System Combined with Multimedia Interactive Model and Virtual Reality Technology[J]. Multimedia Tools and Applications, 2019(2): 1-15. 